\title{
Synthesis of dibenzosuberenone-based novel polycyclic $\pi$-conjugated dihydropyridazines, pyridazines and pyrroles
}

\author{
Ramazan Koçak and Arif Daştan *
}

\author{
Full Research Paper \\ Address: \\ Department of Chemistry, Faculty of Sciences, Atatürk University, \\ Erzurum, 25240, Turkey \\ Email: \\ Arif Daştan* - adastan@atauni.edu.tr \\ ${ }^{*}$ Corresponding author \\ Keywords: \\ dibenzosuberenone; inverse electron-demand Diels-Alder \\ cycloaddition reactions; $p$-quinone methide; polycyclic $\Pi$-conjugated \\ dihydropyridazines; pyridazines; pyrroles
}

Beilstein J. Org. Chem. 2021, 17, 719-729.

https://doi.org/10.3762/bjoc.17.61

Received: 10 January 2021

Accepted: 26 February 2021

Published: 15 March 2021

Associate Editor: B. Nay

(C) 2021 Koçak and Daştan; licensee Beilstein-Institut. License and terms: see end of document.

\begin{abstract}
The synthesis of novel polycyclic $\pi$-conjugated dihydropyridazines, pyridazines, and pyrroles was studied. Dihydropyridazine dyes were synthesized by inverse electron-demand Diels-Alder cycloaddition reactions between a dibenzosuberenone and tetrazines that bear various substituents. The pyridazines were synthesized in high yields by oxidation of dihydropyridazine-appended dibenzosuberenones with PIFA or NO. $p$-Quinone derivatives of pyridazines were also obtained by H-shift isomerization following the inverse electron-demand Diels-Alder reaction of tetrazines with $p$-quinone dibenzosuberenone. Then these pyridazines were converted to the corresponding pyrroles by reductive treatment with zinc. It was observed that all the dihydropyridazines obtained gave absorbance and emission at long wavelengths.
\end{abstract}

\section{Inroduction}

Dibenzosuberone and dibenzosuberenone derivatives are commonly used for the synthesis of biologically active compounds having enzyme inhibition and antiviral activity [1,2], and are found in the structures of many commercially available antidepressant drugs [3-12]. In addition, dibenzosuberenone (1) and polyconjugated derivatives exhibit photophysical properties such as photosensitization [13], fluorescence, and aggregationinduced emission (AIE) [14-16].

$\pi$-Conjugated polycyclic hydrocarbons (CPHs) containing polycyclic heteroaromatic molecules (PHAs) and aza-polycyclic ar- omatic hydrocarbons (aza-PAHs) have been attracting considerable attention as they are widespread in natural products, as well as in pharmaceuticals, agrochemicals, and organic materials. Among the $\pi$-CPHs, pyridazines and pyrroles have important roles [17-22].

Although there are very few pyridazine ring-containing compounds isolated from nature (pyridazomycin, pyridazocidin, and azamerone (Figure 1)) [23-25], numerous pyridazine derivatives have been synthesized and used in a wide variety of biochemical and physicochemical applications. Examples of 
<smiles>O=c1c2ccccc2ccc2ccccc12</smiles>

dibenzosuberenone 1<smiles>CCN(C)CCNc1nnc(-c2ccccc2)cc1C</smiles>
minaprine<smiles></smiles>

cyproheptadine<smiles>CN(C)CCC=C1c2ccccc2C=Cc2ccccc21</smiles>

cyclobenzaprine<smiles>CC(=O)c1nncc2c1C(=O)C1=C(O[C@](C)(O)[C@H](Cl)C1)C2(O)C[C@@H]1C(C)(C)C(Cl)CC[C@]1(C)O</smiles>

azamerone

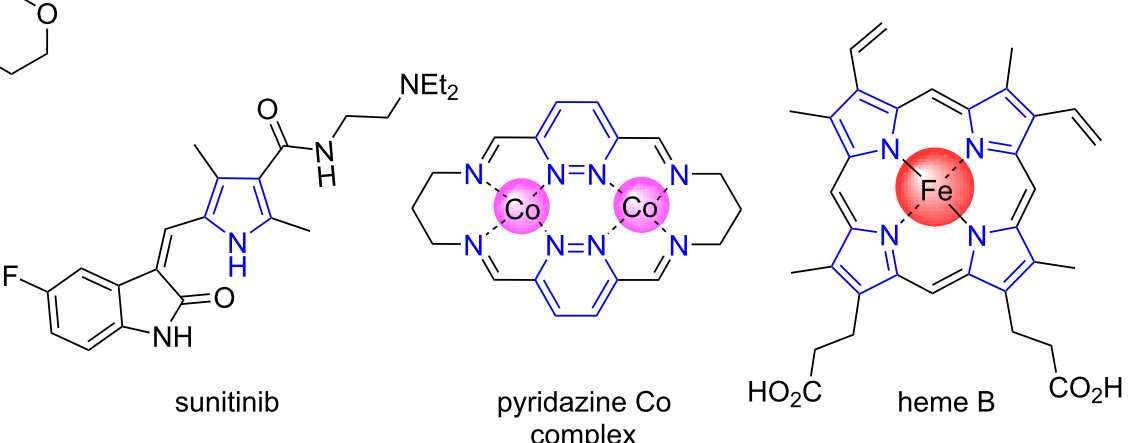
complex

Figure 1: Structures of dibenzosuberenone 1 and pyridazine and pyrrole derivatives.

these applications are as drug ingredients [26-31]; for their analgesic, anticancer, antihypertensive, anti-Parkinson, anti-inflammatory, anticonvulsant, vasodilatory, antidiabetic, antitubercular, antifungal, and antibacterial activities [32-38], pH-sensing [39], OLEDs [40], chemiluminescent materials [41,42], metal complexes (Figure 1) [43-46], liquid crystal [47], and self-assembled supramolecular architectures [48].

On the other hand, many natural compounds that contain a pyrrole core, such as bilirubin, hemoglobin, chlorophyll a, and vitamin B12, are very important for life. In addition to being common in natural products and biological systems, the active ingredient of many top-selling drugs such as atorvastatin, sunitinib, and ketorolac, contains a pyrrole unit (Figure 1) [49].

Due to these unique features, the synthesis of new dihydropyridazines, pyridazines, and pyrroles, which have the potential to be used in many applications, is very important. inverse electron-demand Diels-Alder cycloaddition reactions of alkenes with tetrazines are commonly used for the synthesis of dihydropyridazines and pyridazines [50-54].

In our previous study, we made a discovery that would form the basis of a new class of dyestuffs with skeletons unlike those of classic organic dyestuffs. In that study, two highly fluorescent dibenzosuberenone-based dihydropyridazine dyes, $\mathbf{3 a}, \mathbf{b}$, were synthesized, and it was found that they can be used as a selective and sensitive sensor of fluoride anions (Scheme 1, Table 1)
[55]. In another work, we reported the design, synthesis, and structural and photophysical characterization of a new series of 3,7-substituted dihydropyridazine dibenzosuberenone units with electron-withdrawing and electron-donating functional groups [56].

Herein, we report the examined impact of various electronwithdrawing and electron-donating functional groups at the 3and 6-positions of $s$-tetrazine on inverse electron-demand Diels-Alder cycloaddition reactions with a dibenzosuberenone (1) and the photophysical properties of dihydropyridazines. The corresponding pyridazines and pyrroles were obtained from dihydropyridazines. Finally, we investigated the photophysical properties of dihydropyridazines.

\section{Results and Discussion Synthesis}

In the first part of the study, we focused on the inverse electrondemand Diels-Alder cycloaddition reactions of dibenzosuberenone (1) with $s$-tetrazines 2a-l (Figure 2), which were synthesized according to the literature procedures ( $\mathbf{2} \mathbf{j}$ was synthesized by acetylation of $\mathbf{2 i}$, while $\mathbf{2 b}$ and $\mathbf{2 g}$ were purchased) [57-63].

When dibenzosuberenone (1) and s-tetrazines $\mathbf{2 a}-\mathbf{j}$ (1.1 equiv) were dissolved in toluene in a sealed tube and stirred at $100-125{ }^{\circ} \mathrm{C}$ for $2-48 \mathrm{~h}$, a sequence of a [4 + 2]-Diels-Alder cycloaddition reaction, a retro Diels-Alder reaction of the re- 


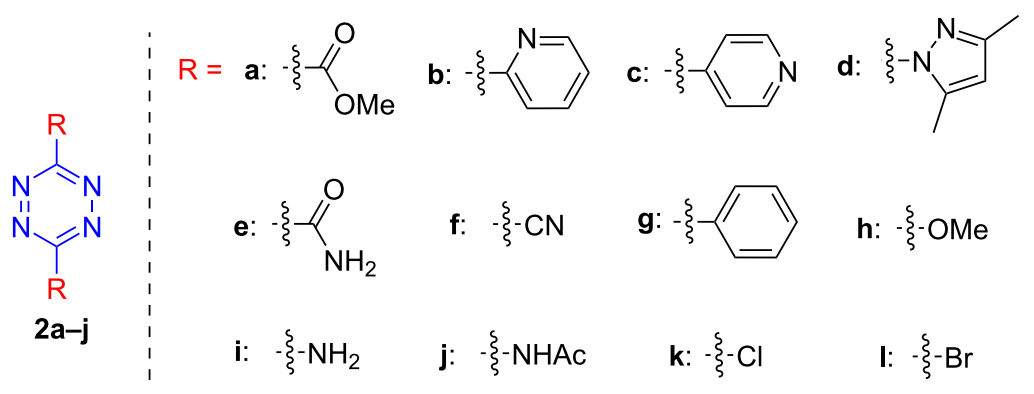

Figure 2: Structures of $s$-tetrazines 2a-I.

sulting adduct, and a final 1,3-prototropic hydrogen shift took place to afford cycloadducts $\mathbf{3 a}, \mathbf{b}[55]$ and $\mathbf{3 c - f}$ (87-96\% yield) (Scheme 1 and Table 1).<smiles>O=c1c2ccccc2ccc2ccccc12</smiles>

1<smiles>[R]c1nnc([R])[nH+]n1</smiles>

2a-I

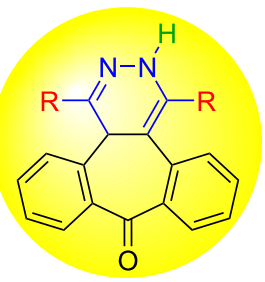

3a-1
Scheme 1: Inverse electron-demand Diels-Alder reactions of dibenzosuberenone (1) with tetrazines $2 a-1$.
As shown by the reaction conditions in Table 1, the reactions of tetrazine derivatives with electron-withdrawing groups (EWGs) 2a-f (4-pyridyl, 3,5-dimethyl- $1 \mathrm{H}$-pyrazol-1-yl, $\mathrm{CONH}_{2}, \mathrm{CN}$ ) resulted in the formation of the target molecules $\mathbf{3 a - f}$ in high yields. However, the reactions of tetrazine derivatives with electron-donating groups (EDGs) $\mathbf{2} \mathbf{g}-\mathbf{j}$ ( $\mathrm{Ph}, \mathrm{OMe}, \mathrm{NH}_{2}, \mathrm{NHAc}$ ) did not work under the same reaction conditions.

Inverse electron-demand Diels-Alder reactions are cycloadditions between electron-rich dienophiles and electron-poor dienes. EDGs raise the electron density of dienes and, in parallel, raise the $\mathrm{LUMO}_{\text {diene }}-\mathrm{HOMO}_{\text {dienophile }}$ energy gap, and consequently the reactivity decreases. Although the tetrazine ring is an electron-poor diene, the dibenzosuberenone (1) dienophile is not electron-rich enough. Therefore, for such cycloaddi-

Table 1: Synthesis of cycloadducts $3 a-1$.

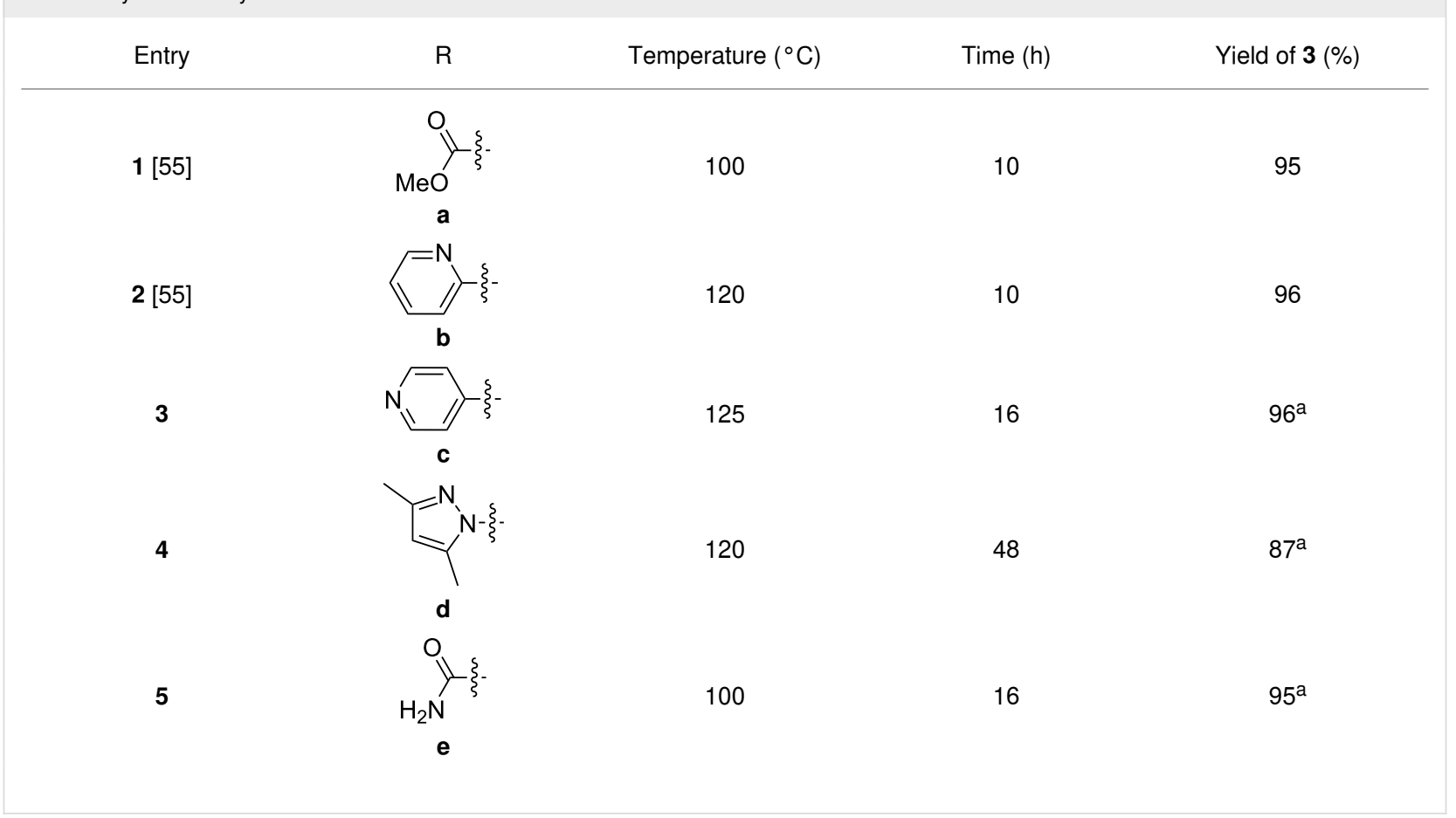


Table 1: Synthesis of cycloadducts 3a-I. (continued)

6

7

8

9

10
NC. $\}$

f<smiles>[Te]c1ccccc1</smiles>

g

$\mathrm{MeO} \cdot \xi$

h

$\left.\mathrm{H}_{2} \mathrm{~N}\right\}$.

i

$\mathrm{AcHN}-\xi$
100

150

150

150

150
48

24

24

aAll reactions were carried using the compounds 1 and $\mathbf{2 a}-\mathbf{I}$ (1.1 equivalents) in toluene in a sealed tube (see the Experimental section in Supporting Information File 1 for details).

tion reactions, the tetrazine must be substituted by EWGs to decrease the electron density of the diene. Consequently, our results confirm that EDGs and EWGs play a crucial role in the reactivity.

It should be noted that, unlike the other tetrazine derivatives, dichlorotetrazine (2k) afforded the addition product $\mathbf{3 k}$ and the oxidation product $\mathbf{4 k}$ as a result of its reaction with dibenzosuberenone (1). When dibromotetrazine (2l) was used, on the other hand, the oxidation product $\mathbf{4 1}$ and an unexpected product, dibromobenzonorbornadiene 5l, were formed (Scheme 2).<smiles>[X]C1=NNC([X])=C2c3ccccc3C(=O)c3ccccc3C12</smiles>

$3 \mathrm{k}, 27 \%$

$3 \mathbf{I}, 0 \%$<smiles>[X]c1nnc([X])c2c3ccccc3c(=O)c3ccccc3c12</smiles>

4k, $33 \%$

$41,46 \%$

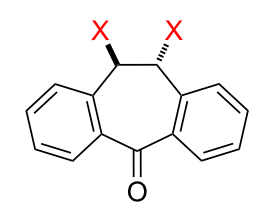

$5 \mathbf{k}, 0 \%$

5I, $30 \%$
Scheme 2: Inverse electron-demand Diels-Alder reactions between dibenzosuberenone $\mathbf{1}$ and tetrazines $\mathbf{2} \mathbf{k}^{\mathrm{a}}$ and $\mathbf{2} \mathrm{I}^{\mathrm{b}}$. ${ }^{\mathrm{a}} 5.55 \mathrm{mmol} \mathbf{1}$, $3.70 \mathrm{mmol} 2 \mathrm{k}, 10 \mathrm{~mL}$ toluene, $120^{\circ} \mathrm{C}, 48$ h. b $4.85 \mathrm{mmol} \mathbf{1}, 0.98 \mathrm{mmol}$ 2I, $100^{\circ} \mathrm{C}$, overnight (solvent free).
The formation of the oxidized products $\mathbf{4 k}$ and $\mathbf{4 l}$ in these reactions was probably due to the properties of tetrazines because they are known to act, in some cases, as oxidizing agents in Diels-Alder reactions, depending on the structure of the diene and the reaction conditions [64]. A proposed reaction mechanism for the formation of the dibenzosuberenone derivatives $\mathbf{3}$ and $\mathbf{4}$ is illustrated in Scheme 3. Although 3k was isolated, $\mathbf{3 l}$ could not be detected in the reaction mixture due to its complete conversion to $\mathbf{4 l}$, revealing its ease of oxidation com-

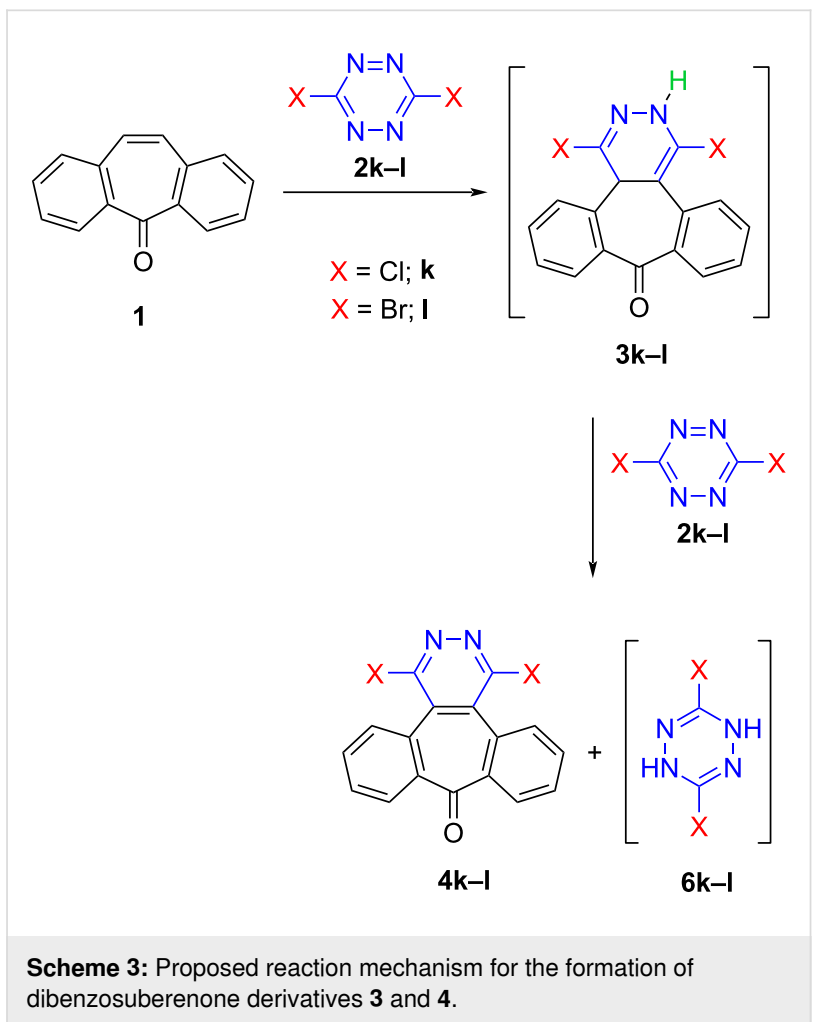


pared to the chloro derivative $3 \mathbf{k}$. In addition, dihydrotetrazines $\mathbf{6 k}$ and $\mathbf{6 l}$ could not be isolated, as probably compound $\mathbf{6 k}$ decomposed completely in the reaction medium and $\mathbf{6}$ decomposed following a bromine transfer to dibenzosuberenone (1, Scheme 3).

The formation of $\mathbf{5 l}$ was also an unexpected result because there has been no precedent reported to date, in which a tetrazine acts as a halogen source in the halogenation of a double bond. Therefore, the formation of $\mathbf{5} \mathbf{l}$ constitutes the first example of this unusual behavior. In the proposed mechanism illustrated in Scheme 4, tetrazine $\mathbf{6}$ first tautomerizes into 7, from which dibenzosuberenone (1) receives bromine to give $\mathbf{5 l}$ via bromonium 8. As tetrazine 9 was unstable under the current reaction conditions, it decomposed and could not be observed [65].

In the second part of the study, dihydropyridazines $\mathbf{3 a - f}$ were oxidized to pyridazines. In contrast to dihydropyridazineamide $\mathbf{3 e}$, the reaction of dihydropyridazines $\mathbf{3 a - d}$ and $\mathbf{3 f}$ with PIFA ([bis(trifluoroacetoxy)iodo]benzene) afforded the corresponding pyridazine derivatives $\mathbf{4 a - d}$ and $\mathbf{4 f}$ in good yields (79-95\%). As a result of the reaction of PIFA with dihydropyridazine 3e, the intended pyridazine compound could not be obtained. Alternatively, nitrogen monoxide (NO) gas was used as oxidizer and pyridazineamide $4 \mathbf{e}$ was obtained in high yield (83\%, Scheme 5).

In another important part of this study, pyridazines were converted into the corresponding pyrroles via a ring contraction under reductive conditions in presence of zinc dust in acetic acid according to the Boger procedure, which is a highly reliable synthetic approach [66-68]. For pyrrole conversions, methoxycarbonyl- and 2-pyridylpyridazine derivatives $\mathbf{4 a}$ and 4b were used.

When methoxycarbonylpyridazine 4 a reacted with 5 equivalents of $\mathrm{Zn}$ in acetic acid at room temperature overnight the corresponding pyrrole 10aa was obtained. When using 10 equivalents of $\mathrm{Zn}$ instead of 5 equivalents, hydroxypyrrole 10ab was formed, in which the carbonyl group was also reduced to the hydroxy group. Then unsubstituted pyrrole 10ac was synthesized by the reaction of pyrrole 10ab with 4 equivalents of $\mathrm{KOH}$ under microwave irradiation (Scheme 6).

The reaction of 2-pyridylpyridazine $\mathbf{4 b}$ with $\mathrm{Zn}$ did not work at room temperature. Under reflux conditions compound 10ba was obtained, which contained the corresponding pyrrole and acetate structures. The acetate is formed by reducing the carbonyl group to alcohol and then reacting this alcohol with acetic acid. After hydrolysis of the acetate group with sodium hydroxide, alcohol derivate $\mathbf{1 0 b b}$ was formed. Oxidation of alcohol $10 b b$ with $\mathrm{MnO}_{2}$ led to the formation of the corresponding ketone 10bc. Eventually, pyrrole derivative 10bc, having a carbonyl group, was obtained by these reactions (Scheme 7).

In order to increase the conjugation of dibenzosuberenone $\mathbf{1}$ for the photophysical aspect, the $p$-quinone methide derivative of dibenzosuberenone $\mathbf{1 1}$ was synthesized according to the method in the literature [69]. The products expected from the reaction of $p$-quinone methide $\mathbf{1 1}$ with tetrazines $\mathbf{2 a , b}$ are dihydropyridazines 12a,b, but this molecule could not be obtained. Instead, surprisingly, products 13a,b were obtained, of which the dihydropyridazine part was oxidized to pyridazine and the $p$-quinone methides part was reduced to phenol. After the

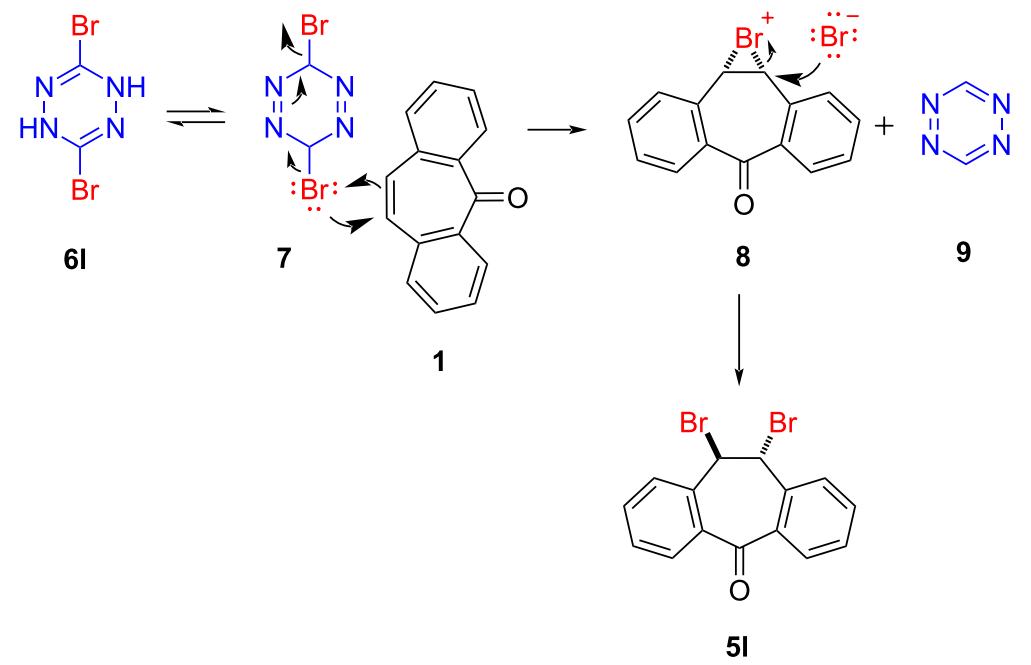

Scheme 4: Proposed mechanism for the formation of 5 I. 

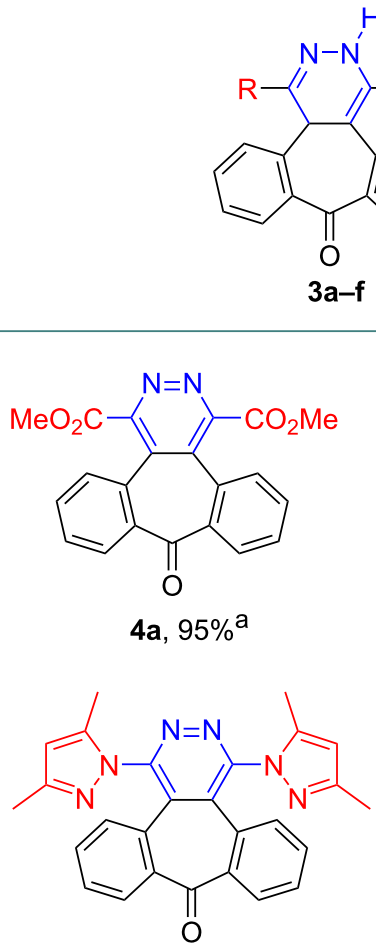

4d, $91 \%{ }^{c}$
$4 a, 95 \%^{a}$<smiles>CC(=O)c1nnc(C(C)=O)c2c3ccccc3c(=O)c3ccccc3c12</smiles>

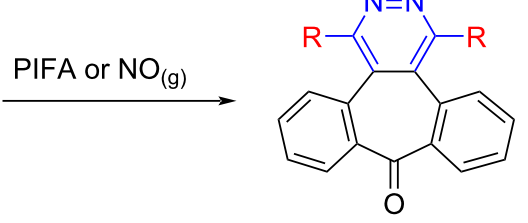

$4 a-f$<smiles>O=c1c2ccccc2c2c(-c3ccccn3)nnc(-c3ccccn3)c2c2ccccc12</smiles>

4b, $90 \%^{a}$<smiles></smiles>

$4 c, 87 \%^{b}$

Scheme 5: Oxidation of dihydropyridazines 3a-f. All reactions were carried in $\mathrm{CH}_{2} \mathrm{Cl}_{2}$ at room temperature $\left(4 \mathrm{e}: 0{ }^{\circ} \mathrm{C}\right) .{ }^{\mathrm{a}} 1.0$ equivalent $\mathrm{PIFA}, 1 \mathrm{~h}$. $\mathrm{b}_{1.5}$ equivalents PIFA, overnight. ${ }^{\mathrm{c}} 1.2$ equivalents PIFA, overnight. ${ }^{\mathrm{d}}$ Nitrous gases were bubbled through a solution of $3 \mathrm{e}$ for $1 \mathrm{~h}$. ${ }^{\mathrm{e}} 1.0$ equivalent PIFA, overnight.<smiles>CC(=O)c1[nH]c(C(C)=O)c2c3ccccc3c(=O)c3ccccc3c12</smiles>

10aa, $82 \%^{a}$

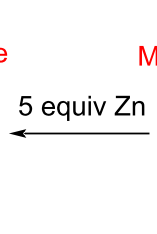<smiles></smiles>

$4 a$

10 equiv $\mathrm{Zn}$<smiles>OC1c2ccccc2-c2c[nH]cc2-c2ccccc21</smiles>

$10 \mathrm{ac}, 70 \%{ }^{\mathrm{b}}$

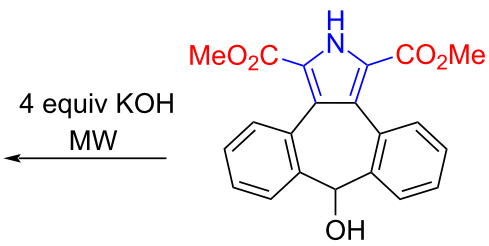

$10 \mathrm{ab}, 74 \%^{\mathrm{a}}$

Scheme 6: Synthesis of pyrrole 10a. ${ }^{a} 1.34 \mathrm{mmol}$ 4a, Zinc (for 10aa: $6.68 \mathrm{mmol}$, for $10 \mathrm{ab}$ : $13.36 \mathrm{mmol}$ ), $10 \mathrm{~mL}$ glacial acetic acid, room temperature, overnight. ${ }^{\mathrm{b}} 0.55 \mathrm{mmol} 10 \mathrm{ab}, 2.20 \mathrm{mmol} \mathrm{KOH}, 5 \mathrm{~mL}$ $\mathrm{THF} / \mathrm{CH}_{3} \mathrm{OH} / \mathrm{H}_{2} \mathrm{O}(2: 2: 1)$ solvent mixture, $150{ }^{\circ} \mathrm{C}, 200 \mathrm{~W}, 2 \mathrm{~h}$.<smiles></smiles>

$4 e, 83 \% d$<smiles>N#Cc1nnc(C#N)c2c3ccccc3c(=O)c3ccccc3c12</smiles>

4f, $79 \%{ }^{\mathrm{e}}$ 
phenolic part of 13a,b was oxidized to $p$-quinone methides with PIFA, 14a and 14b were synthesized in $87 \%$ and $91 \%$ yields, respectively. Moreover, by submitting 13a,b to reductive conditions in presence of $\mathrm{Zn}$, the pyridazine part of $\mathbf{1 3 a} \mathbf{a}, \mathbf{b}$ was converted to pyrrole 15a,b. Finally, the phenolic parts of 15a,b were oxidized to $p$-quinone methides $\mathbf{1 6 a}, \mathbf{b}$ with PIFA in excellent yield (89-97\%, Scheme 8).

For the formation of unexpected compound 13, we propose two different mechanisms. First, following the formation of phenolic tautomer 12A by tautomerization A with a [1,7]-H shift 13 would be formed. Alternatively, in the second mechanism, $\mathbf{1 3}$ is thought to occur by tautomerization B and a [1,5]-H shift (Scheme 9).

\section{Photophysical properties}

In our previous work, we examined the photophysical and fluoride sensing properties of dihydropyridazine fluorescent dyes 3a,b in detail. In the present study, the effects of functional groups with different conjugations on maximum absorbance $\left(\lambda_{\max }\right.$, abs $)$ and emission $\left(\lambda_{\max }\right.$, ems $)$, and wavelengths of dihydropyridazines $\mathbf{3 c - f}$ and $\mathbf{3 k}$ were investigated. Compounds $\mathbf{3 c}, \mathbf{d}$, with high conjugation, show the highest absorption and emission maxima values and compounds $\mathbf{3 f}$ and $\mathbf{3 k}$, with low conjugation, show the lowest absorption and emission maxima values (Figure 3, Figure 4, and Figure 5). All these molecules (3c-f and 3k) have Stokes shifts greater than $100 \mathrm{~nm}$. The fluorescence quantum yields of $\mathbf{3 c - f}$ and $\mathbf{3 k}$ were calculated by comparison with a well-known reference, quinine sulfate, in $0.5 \mathrm{M} \mathrm{H}_{2} \mathrm{SO}_{4}$ solution $\left(\Phi_{\mathrm{F}}=0.546\right)$ as the standard dye (Table 2). When the UV-vis and fluorescence spectra of pyridazines and pyrroles were examined, it was seen that generally, they did not have effective absorbance or emission intensity. Although all $\pi$-conjugated pyridazines and pyrroles known in the literature did not show high emission, along with other photophysical properties the excellent coordination ability and especially their importance in biological systems always make these compounds valuable.<smiles>O=C1C=CC(=C2c3ccccc3C=Cc3ccccc32)C=C1</smiles>

11<smiles>[R]C1=NNC([R])=C2C(CC)c3ccccc3C(=C3C=CC(=O)C=C3)c3ccccc3C12</smiles>

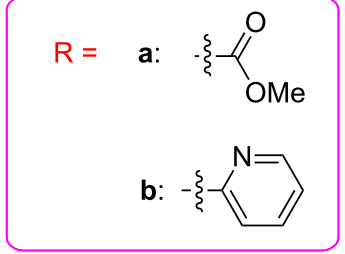<smiles>[R]c1nnc([R])c2c1-c1ccccc1C(c1ccc(O)cc1)c1ccccc1-2</smiles>

13a, $95 \%^{\mathrm{a}}$

$13 b, 93 \%^{a}$ PIFA

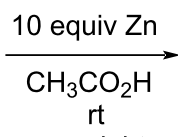
overnight<smiles>[R]c1[nH]c([R])c2c1-c1ccccc1C(c1ccc(O)cc1)c1ccccc1-2</smiles>

$15 a, 62 \%{ }^{c}$

$15 \mathrm{~b}, 57 \%^{\mathrm{c}}$<smiles>[R]c1nnc([R])c2c1-c1ccccc1C(=C1C=CC(=O)C=C1)c1ccccc1-2</smiles>

$14 a, 90 \%^{b}$

$14 b, 87 \%^{b}$<smiles>[R]c1[nH]c([R])c2c1-c1ccccc1C(=C1C=CC(=O)C=C1)c1ccccc1-2</smiles>

$16 a, 89 \%{ }^{d}$

Scheme 8: Synthesis of $p$-quinone methides 13-16. ${ }^{\mathrm{a}} 1.77 \mathrm{mmol} \mathrm{11,} 1.77 \mathrm{mmol}$ 2, $5 \mathrm{~mL}$ toluene, $80^{\circ} \mathrm{C}$ (13a: overnight, 13b: 3 days). ${ }^{b} 1.11 \mathrm{mmol} \mathbf{1 3}$

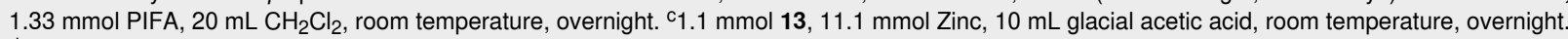

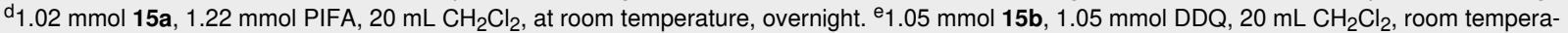
ture, $30 \mathrm{~min}$. 
<smiles></smiles>

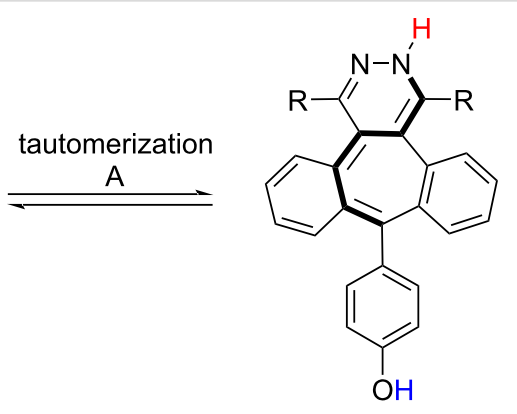

phenolic tautomer $12 \mathrm{~A}$<smiles>[R]c1nnc([R])c2c1-c1ccccc1C(c1ccccc1)(c1ccc(O)cc1)c1ccccc1-2</smiles>

13 tautomer 12

$\{$ tautomerization<smiles></smiles>

phenolic tautomer<smiles>[R]c1nnc([R])c2c1-c1ccccc1C(c1ccc(O)cc1)c1ccccc1-2</smiles>

13

Scheme 9: Proposed mechanism for the formation of 13.

Table 2: Some photophysical properties of cycloadducts $\mathbf{3 c - 3 f}$ and $\mathbf{3 k}$.

\begin{tabular}{rrrrr} 
Compound & $\lambda_{\mathrm{ems}} / \mathrm{nm}^{\mathrm{a}}\left(\lambda_{\mathrm{exc}} / \mathrm{nm}\right)$ & $\lambda_{\mathrm{abs}} / \mathrm{nm}[\mathrm{a}]$ & Stokes shift $(\mathrm{nm})$ & Quantum yields $\left(\Phi_{\mathrm{F}}\right)$ \\
\hline 3c & $534(400)$ & 427 & 107 & 0.78 \\
3d & $539(375)$ & 408 & 131 & 0.60 \\
3e & $515(360)$ & 393 & 122 & 0.53 \\
3f & $487(350)$ & 378 & 109 & 0.28 \\
3k & $503(350)$ & 378 & 125 & 0.16 \\
\hline
\end{tabular}

${ }^{\mathrm{a}} \mathrm{C}=5 \mu \mathrm{M}\left(\mathrm{CH}_{3} \mathrm{CN}\right)$.

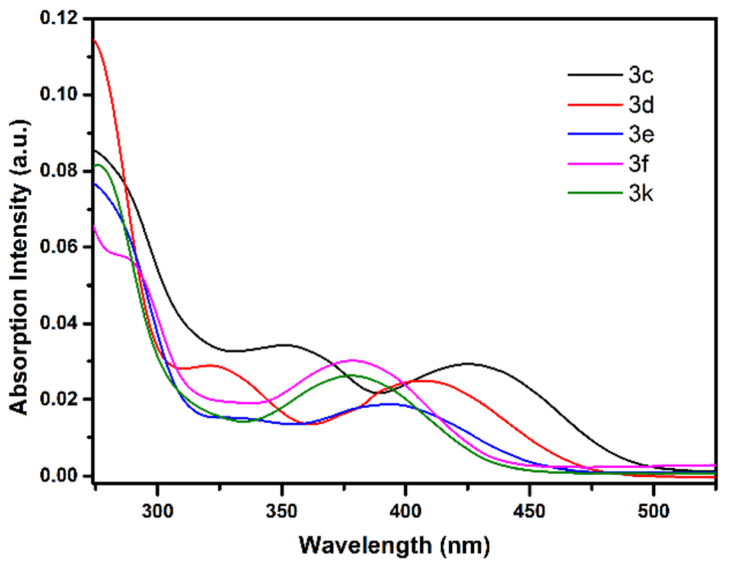

Figure 3: UV-vis spectra of $\mathbf{3} \mathbf{c}-\mathbf{f}$ and $\mathbf{3 k}$ in $\mathrm{CH}_{3} \mathrm{CN}$ at rt $(c=5 \mu \mathrm{M})$.

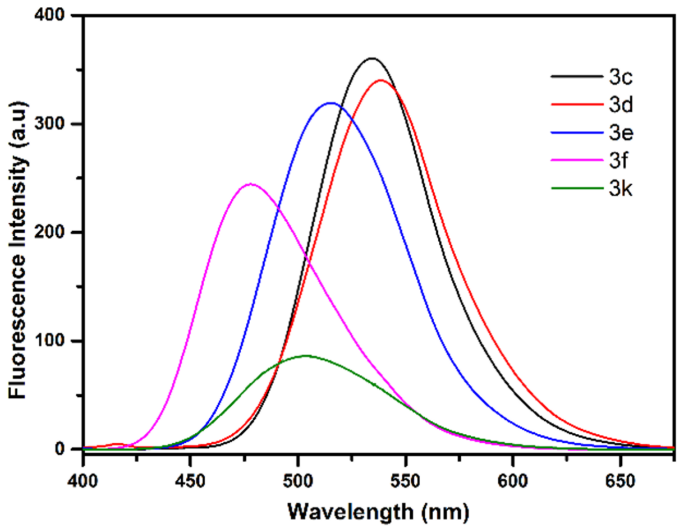

Figure 4: Fluorescence spectra of $3 \mathbf{c}-\mathbf{f}$ and $\mathbf{3 k}$ in $\mathrm{CH}_{3} \mathrm{CN}$ at rt $(c=5 \mu \mathrm{M})$. 


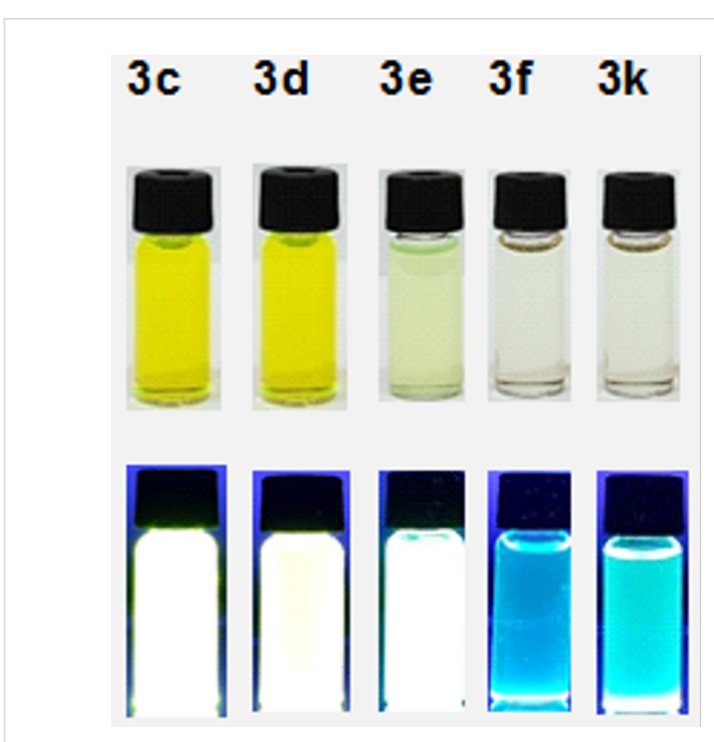

Figure 5: Ambient (top) and fluorescence (bottom, under $365 \mathrm{~nm}$ UV light) images of $\mathbf{3 c - f}$ and $\mathbf{3 k}$ in $\mathrm{CH}_{3} \mathrm{CN}$.

\section{Conclusion}

Novel polycyclic $\pi$-conjugated dibenzosuberenone-based dihydropyridazine dyes were synthesized by inverse electrondemand Diels-Alder cycloaddition reactions between dibenzosuberenone (1) and tetrazines bearing various substituents. These products showed long absorption wavelengths and emission bands, large Stokes shifts, and good fluorescence quantum yields. The dihydropyridazines were oxidized into pyridazines and then converted to pyrroles. Moreover, $p$-quinone methide derivatives of dibenzosuberenone-based pyridazines and pyrroles were synthesized. We continue intensively to perform various photochemical and biochemical studies on these compounds, which have the potential to be used in chemosensors, light harvesting, organic optoelectronics, metal coordination complexes and other photophysical applications and in biological systems.

\section{Supporting Information}

\section{Supporting Information File 1}

Experimental procedures, copies of ${ }^{1} \mathrm{H}$ NMR, ${ }^{13} \mathrm{C}$ NMR, and HRMS(Q-TOF) spectra.

[https://www.beilstein-journals.org/bjoc/content/ supplementary/1860-5397-17-61-S1.pdf]

\section{Funding}

We are grateful to The Scientific and Technological Research Council of Turkey (TUBİTAK) (Project number KBAG215Z445) for financial support.

\section{ORCID ${ }^{\circledR}$ iDs}

Ramazan Koçak - https://orcid.org/0000-0002-5016-2767

\section{References}

1. Koeberle, S. C.; Fischer, S.; Schollmeyer, D.; Schattel, V.; Grütter, C.; Rauh, D.; Laufer, S. A. J. Med. Chem. 2012, 55, 5868-5877. doi:10.1021/jm300327h

2. Murray, M. A.; Babe, L. M. Antiviral Res. 1999, 44, 123-131. doi:10.1016/s0166-3542(99)00061-3

3. Silver, H.; Blacker, M.; Weller, M. P. I.; Lerer, B. Biol. Psychiatry 1989, 25, 502-504. doi:10.1016/0006-3223(89)90206-0

4. Andersen, J. M.; Sugerman, K. S.; Lockhart, J. R.; Weinberg, W. A. Pediatrics 1997, 100, 977-981. doi:10.1542/peds.100.6.977

5. Wilens, T. E.; Biederman, J.; Geist, D. E.; Steingard, R.; Spencer, T. J. Am. Acad. Child Adolesc. Psychiatry 1993, 32, 343-349. doi:10.1097/00004583-199303000-00015

6. Prince, J. B.; Wilens, T. E.; Biederman, J.; Spencer, T. J.; Millstein, R.; Polisner, D. A.; Bostic, J. Q. J. Child Adolesc. Psychopharmacol. 2000, 10, 193-204. doi:10.1089/10445460050167304

7. Thompson, C. Br. J. Psychiatry 2001, 178, 99-100. doi:10.1192/bjp.178.2.99

8. Buschmann, H.; Díaz, J. L.; Holenz, J.; Párraga, A.; Torrens, A.; Vela, J. M. Antidepressants, antipsychotics, anxiolytics from chemistry and pharmacology to clinical application; Wiley-VCH: Weinheim, Germany, 2007; Vol. 1 \& 2. doi:10.1002/9783527619337

9. Sittig, M. Pharmaceutical manufacturing encyclopedia; Noyes Publications: Park Ridge, NJ, USA, 1988.

10. Paykel, E. S. Handbook of affective disorders; The Guilford Press: New York, NY, USA, 1992.

11. Vaugeois, J.-M.; Corera, A. T.; Deslandes, A.; Costentin, J. Pharmacol., Biochem. Behav. 1999, 63, 285-290. doi:10.1016/s0091-3057(98)00242-1

12. Chou, R.; Peterson, K.; Helfand, M. J. Pain Symptom Manage. 2004, 28, 140-175. doi:10.1016/j.jpainsymman.2004.05.002

13. Bume, D. D.; Pitts, C. R.; Jokhai, R. T.; Lectka, T. Tetrahedron 2016, 72, 6031-6036. doi:10.1016/j.tet.2016.08.018

14. Wang, Z.; Shao, H.; Ye, J.; Tang, L.; Lu, P. J. Phys. Chem. B 2005, 109, 19627-19633. doi:10.1021/jp053113j

15. Shao, H.; Chen, X.; Wang, Z.; Lu, P. J. Phys. Chem. B 2007, 111, 10386-10396. doi:10.1021/jp073767n

16. Brosius, V.; Müller, M.; Borstelmann, J.; Rominger, F.; Freudenberg, J.; Bunz, U. H. F. J. Org. Chem. 2020, 85, 296-300. doi:10.1021/acs.joc.9b02756

17. Hirai, M.; Tanaka, N.; Sakai, M.; Yamaguchi, S. Chem. Rev. 2019, 119, 8291-8331. doi:10.1021/acs.chemrev.8b00637

18. Shankar, M.; Ghosh, K.; Mukherjee, K.; Rit, R. K.; Sahoo, A. K. Org. Lett. 2016, 18, 6416-6419. doi:10.1021/acs.orglett.6b03314

19. Stępień, M.; Gońka, E.; Żyła, M.; Sprutta, N. Chem. Rev. 2017, 117, 3479-3716. doi:10.1021/acs.chemrev.6b00076

20. Huang, R.; Phan, H.; Herng, T. S.; Hu, P.; Zeng, W.; Dong, S.-q.; Das, S.; Shen, Y.; Ding, J.; Casanova, D.; Wu, J. J. Am. Chem. Soc. 2016, 138, 10323-10330. doi:10.1021/jacs.6b06188

21. Kethe, A.; Li, A.; Klumpp, D. A. Tetrahedron 2012, 68, 3357-3360. doi:10.1016/j.tet.2012.02.047

22. Zheng, X.; Su, R.; Wang, Z.; Wang, T.; Bin, Z.; She, Z.; Gao, G.; You, J. Org. Lett. 2019, 21, 797-801. doi:10.1021/acs.orglett.8b04059

23. Bockholt, H.; Beale, J. M.; Rohr, J. Angew. Chem., Int. Ed. Engl. 1994, 33, 1648-1651. doi:10.1002/anie.199416481 
24. Gerwick, B. C.; Fields, S. S.; Graupner, P. R.; Gray, J. A.; Chapin, E. L.; Cleveland, J. A.; Heim, D. R. Weed Sci. 1997, 45, 654-657.

25. Wermuth, C. G. Med. Chem. Commun. 2011, 2, 935-941. doi:10.1039/c1md00074h

26. Worms, P.; Kan, J.-P.; Steinberg, R.; Terranova, J.-P.; Perio, A.; Biziere, K. Naunyn-Schmiedeberg's Arch. Pharmacol. 1989, 340 , 411-418. doi:10.1007/bf00167042

27. Biziere, K.; Worms, P.; Kan, J.; Mandel, P.; Garattini, S.; Roncucci, R. Drugs Exp. Clin. Res. 1985, 11, 831-840.

28. McTavish, D.; Young, R. A.; Clissold, S. P. Drugs 1990, 40, 543-560. doi:10.2165/00003495-199040040-00005

29. lizawa, Y.; Okonogi, K.; Hayashi, R.; Iwahi, T.; Yamazaki, T.; Imada, A. Antimicrob. Agents Chemother. 1993, 37, 100-105. doi:10.1128/aac.37.1.100

30. Aleeva, G. N.; Molodavkin, G. M.; Voronina, T. A. Bull. Exp. Biol. Med. 2009, 148, 54-56. doi:10.1007/s10517-009-0638-4

31. Rezaei, Z.; Sharbaf, F. R.; Pourmojieb, M.; Youefzadeh-Fard, Y.; Motevalian, M.; Khazaeipour, Z.; Esmaeili, S. Acta Med. Iran. 2011, 701-706.

32. Bansal, R.; Kumar, D.; Carron, R.; de la Calle, C. Eur. J. Med. Chem. 2009, 44, 4441-4447. doi:10.1016/j.ejmech.2009.06.006

33. Islam, M.; Siddiqui, A. A.; Rajesh, R. Acta Pol. Pharm. 2008, 65, 353-362.

34. Banerjee, P.; Sharma, P.; Nema, R. Int. J. ChemTech Res. 2009, 1, 522-525.

35. Rathish, I. G.; Javed, K.; Bano, S.; Ahmad, S.; Alam, M. S.; Pillai, K. K. Eur. J. Med. Chem. 2009, 44, 2673-2678. doi:10.1016/j.ejmech.2008.12.013

36. Rathish, I. G.; Javed, K.; Ahmad, S.; Bano, S.; Alam, M. S.; Akhter, M.; Pillai, K. K.; Ovais, S.; Samim, M. Eur. J. Med. Chem. 2012, 49, 304-309. doi:10.1016/j.ejmech.2012.01.026

37. Siddiqui, A. A.; Mishra, R.; Shaharyar, M.; Husain, A.; Rashid, M.; Pal, P. Bioorg. Med. Chem. Lett. 2011, 21, 1023-1026. doi:10.1016/j.bmcl.2010.12.028

38. Al-Harbi, N. O.; Bahashwan, S. A.; Shadid, K. A. J. Am. Sci. 2010, 6, 353-357.

39. Do, J.; Kim, Y.; Attias, A.-J.; Kreher, D.; Kim, E. J. Nanosci. Nanotechnol. 2010, 10, 6874-6878. doi:10.1166/jnn.2010.2955

40. Lincker, F.; Kreher, D.; Attias, A.-J.; Do, J.; Kim, E.; Hapiot, P.; Lemaitre, N.; Geffroy, B.; Ulrich, G.; Ziessel, R. Inorg. Chem. 2010, 49, 3991-4001. doi:10.1021/ic901925w

41. Atılgan, N.; Algı, F.; Önal, A. M.; Cihaner, A. Tetrahedron 2009, 65, 5776-5781. doi:10.1016/j.tet.2009.05.019

42. Asil, D.; Cihaner, A.; Önal, A. M. Electrochim. Acta 2009, 54, 6740-6746. doi:10.1016/j.electacta.2009.06.053

43. Yu, Q.; Zhang, A.-S.; Hu, T.-L.; Bu, X.-H. Solid State Sci. 2010, 12, 1484-1489. doi:10.1016/j.solidstatesciences.2010.06.013

44. Panigati, M.; Donghi, D.; D'Alfonso, G.; Mercandelli, P.; Sironi, A.; D'Alfonso, L. Inorg. Chem. 2006, 45, 10909-10921. doi:10.1021/ic061467z

45. Donghi, D.; D’Alfonso, G.; Mauro, M.; Panigati, M.; Mercandelli, P.; Sironi, A.; Mussini, P.; D’Alfonso, L. Inorg. Chem. 2008, 47, 4243-4255. doi:10.1021/ic7023692

46. Beckmann, U.; Brooker, S. Coord. Chem. Rev. 2003, 245, 17-29. doi:10.1016/s0010-8545(03)00030-4

47. Park, Y. S.; Kim, D.; Lee, H.; Moon, B. Org. Lett. 2006, 8, 4699-4702. doi:10.1021/ol061711q
48. Cuccia, L. A.; Lehn, J.-M.; Homo, J.-C.; Schmutz, M. Angew. Chem., Int. Ed. 2000, 39, 233-237. doi:10.1002/(sici)1521-3773(20000103)39:1<233::aid-anie233>3.0.co; 2-r

49. Joule, J. A.; Mills, K. Heterocyclic chemistry; John Wiley \& Sons: Chichester, UK, 2008.

50. Saracoglu, N. Tetrahedron 2007, 63, 4199-4236. doi:10.1016/j.tet.2007.02.051

51. Schoch, J.; Wiessler, M.; Jäschke, A. J. Am. Chem. Soc. 2010, 132, 8846-8847. doi:10.1021/ja102871p

52. Devaraj, N. K.; Upadhyay, R.; Haun, J. B.; Hilderbrand, S. A.; Weissleder, R. Angew. Chem., Int. Ed. 2009, 48, 7013-7016. doi:10.1002/anie.200903233

53. Kocak, R.; Akın, E. T.; Kalın, P.; Talaz, O.; Saracoglu, N.; Dastan, A.; Gülcin, I.; Durdagi, S. J. Heterocycl. Chem. 2016, 53, 2049-2056. doi:10.1002/jhet.2558

54. Kocak, R.; Dastan, A.; Saracoglu, N. J. Heterocycl. Chem. 2018, 55 , 1489-1493. doi:10.1002/jhet.3180

55. Koçak, R.; Yıldız, D.; Bozkaya, U.; Daştan, A.; Bozdemir, Ö. A. Tetrahedron Lett. 2017, 58, 2981-2985. doi:10.1016/j.tetlet.2017.06.059

56. Erdoğan, M.; Daştan, A. Tetrahedron 2020, 76, 131271. doi:10.1016/j.tet.2020.131271

57. Robins, L. I.; Carpenter, R. D.; Fettinger, J. C.; Haddadin, M. J.; Tinti, D. S.; Kurth, M. J. J. Org. Chem. 2006, 71, 2480-2485. doi:10.1021/j0052577a

58. Farha, O. K.; Malliakas, C. D.; Kanatzidis, M. G.; Hupp, J. T. J. Am. Chem. Soc. 2010, 132, 950-952. doi:10.1021/ja909519e

59. Li, Y.; Asadi, A.; Perrin, D. M. J. Fluorine Chem. 2009, 130, 377-382. doi:10.1016/j.jfluchem.2008.12.006

60. Vo, H.-L.; Arthur, J. L.; Capdevila-Cortada, M.; Lapidus, S. H.; Stephens, P. W.; Novoa, J. J.; Arif, A. M.; Nagi, R. K.; Bartl, M. H.; Miller, J. S. J. Org. Chem. 2014, 79, 8189-8201. doi:10.1021/j05014004

61. Ishmetova, R. I.; Latosh, N. I.; Ganebnykh, I. N.; Ignatenko, N. K.; Tolshchina, S. G.; Rusinov, G. L. Russ. J. Org. Chem. 2009, 45, 1102-1107. doi:10.1134/s1070428009070197

62. Glidewell, C.; Lightfoot, P.; Royles, B. J. L.; Smith, D. M. J. Chem. Soc., Perkin Trans. 2 1997, 1167-1174. doi:10.1039/a607646g

63. Abdo, M.; Brown, S. P.; Courter, J. R.; Tucker, M. J.; Hochstrasser, R. M.; Smith, A. B., III. Org. Lett. 2012, 14, 3518-3521. doi:10.1021/ol301490h

64. Benson, S. C.; Palabrica, C. A.; Snyder, J. K. J. Org. Chem. 1987, 52, 4610-4614. doi:10.1021/jo00229a034

65. Degtyarenko, A. S.; Solntsev, P. V.; Krautscheid, H.; Rusanov, E. B.; Chernega, A. N.; Domasevitch, K. V. New J. Chem. 2008, 32 , 1910-1918. doi:10.1039/b801231h

66. Bach, N. J.; Kornfeld, E. C.; Jones, N. D.; Chaney, M. O.; Dorman, D. E.; Paschal, J. W.; Clemens, J. A.; Smalstig, E. B. J. Med. Chem. 1980, 23, 481-491. doi:10.1021/jm00179a003

67. Boger, D. L.; Coleman, R. S.; Panek, J. S.; Yohannes, D. J. Org. Chem. 1984, 49, 4405-4409. doi:10.1021/jo00197a015

68. Boger, D. L.; Patel, M. J. Org. Chem. 1988, 53, 1405-1415. doi:10.1021/jo00242a013

69. Taljaard, B.; Taljaard, J. H.; Imrie, C.; Caira, M. R. Eur. J. Org. Chem. 2005, 2607-2619. doi:10.1002/ejoc.200400754 


\section{License and Terms}

This is an Open Access article under the terms of the Creative Commons Attribution License (https://creativecommons.org/licenses/by/4.0). Please note that the reuse, redistribution and reproduction in particular requires that the author(s) and source are credited and that individual graphics may be subject to special legal provisions.

The license is subject to the Beilstein Journal of Organic Chemistry terms and conditions:

(https://www.beilstein-journals.org/bjoc/terms)

The definitive version of this article is the electronic one which can be found at:

https://doi.org/10.3762/bjoc.17.61 